\title{
Commonplace
}

\section{Researchers' Perspectives on the Purpose and Value of the Monograph}

David Clark ${ }^{1}$, Mandy Hill ${ }^{2}$

${ }^{1}$ Oxford University Press, ${ }^{2}$ Cambridge University Press

Published on: Jun 22, 2020

DOI: $10.21428 / 6 \mathrm{ffd} 8432.6489 \mathrm{~b} 1 \mathrm{ba}$

License: Creative Commons Attribution 4.0 International License (CC-BY 4.0). 


\section{Foreword}

In October 2019, Oxford University Press and Cambridge University Press joined forces to investigate the purpose and value of the monograph for researchers. The resounding response was that monographs remain key to academic research, both from a career and an epistemological point of view: 'Monographs are the anchors of a discipline, providing solid islands or way markers in an ever expanding sea of research'. However, we also found, unsurprisingly, that the monograph must evolve to support the production and publication of creative and innovative academic work in an increasingly digital world.

And then, along came a global pandemic that has changed how researchers, authors, students, and lecturers interact with scholarly materials, almost overnight. Access to relevant academic resources has been opened up, new ways of delivering teaching have been adopted, while researchers, dependent on physical books pulled down from library shelves, have turned to digital, some for the first time. Now, as the acute impacts of the pandemic begin to pass, we begin to look to what this abrupt shift will mean for distance learning and remote research in the long term.

Our original report pointed towards a digital future, but we are now facing it much sooner than expected. In light of this, we returned to the original survey responses to understand more about the use of digital monographs and to enrich our understanding of and response to the altered research setting.

In the original survey, we asked scholars in Humanities and Social Sciences to think about reading, writing, and publishing monographs - what they would change if they could improve one aspect? The group of almost 5,000 respondents comprised researchers of all ages, in a wide range of countries, at different stages of their academic careers, and yet, despite their disparate backgrounds, three clear themes emerged. Readers want to see:

1. Digital options with stellar content

2. Enhanced usability

3. A fully functional format

They told us that they would like technology employed to provide dynamic, interactive works with fully embedded multimedia content. But they also told us that the allure of the page has not dimmed - readers appreciate e-books that retain traditional page 
numbers and want technology to translate the experience of the physical book into an online version that can be fully highlighted and annotated. They felt that digital monographs even have the potential to support the needs of a typical scholar better than the traditional printed format, performing searches on specific terms to immediately identify the relevant content. Looking back over the results of our original survey, it was clear that the possibilities of an increasingly digital future are already crystallizing for the readers and writers of the monograph.

In our last report, we concluded that the monograph 'must evolve to remain relevant to the way academics work in an increasingly digital world'. While this is still true, the current crisis means we now need to look at how to catalyze this evolution into a speedier revolution. The technology exists, the requirements are clear - what we need to do now is to harness this with creative thinking to ensure the monograph remains the 'gold standard' of academic research in the years to come.

David Clark, Managing Director, Academic Division, Oxford University Press Mandy Hill, Managing Director, Academic Division, Cambridge University Press May 2020

\section{Introduction}

The COVID-19 pandemic has prompted a necessity for the academic community to respond quickly to researchers' needs. As the shift to digital accelerates rapidly, here we take another look at some of the findings from the large-scale survey, jointly undertaken by Cambridge University Press and Oxford University Press in the summer of 2019, with nearly 5,000 usable responses. The survey set out to understand the value of monographs to researchers, to hear the voices of researchers on the relationship between monographs and their research activities.

This is a supplementary report, presenting specific insights about how researchers use and engage with monographs, including what they want as the format evolves in a digital environment. This report should be interpreted alongside the full report, which can be accessed here. 


\section{Key Findings}

\section{Using and engaging with monographs in all formats}

Readers typically engage with monographs on a chapter level or by using references and headings as well as by searching for keywords. When accessing a monograph, over $80 \%$ of respondents indicated they were 'extremely' or 'very' likely to read specific chapters.

Readers are typically less likely to read a monograph cover-to-cover. Early career respondents are more likely to read specific chapters, find references, and search for specific keywords. In mid-career, respondents are more likely to annotate and mark sections for reuse. Late career researchers are more likely to read monographs coverto cover.

Respondents report spending a large part of their reading time with monographs, roughly equal with journal articles, in all regions and at all career stages. Respondents in the Humanities spend more of their reading time with monographs compared to those in the Social Sciences.

A majority of respondents are 'extremely' or 'very' likely to read or refer to monographs in research and teaching, as well as for enjoyment, general interest, and discovering new topics and thinking.

Monographs are used as reference sources to build bibliographies and discover relevant references. They are also important as syntheses of literature in the field, valued for their comprehensive, in-depth, and definitive perspectives. Monographs are used as well to keep up-to-date on the latest thinking and to follow the work of specific authors.

\section{What do researchers want as monographs evolve digitally?}

Respondents were asked to think broadly about reading, writing, and publishing monographs and what they would change if they could change one thing. While the core form and function of the monograph is expected to endure, respondents made suggestions about how changes to content, format, and dissemination could keep the form relevant in the future.

Further analysis was undertaken on a sub-set of this feedback, where responses related to reading and using monographs in a digital environment. Three clear themes 
emerged: readers want to improve the content, usability and format of digital monographs (including e-books).

More specifically, this included improving search capabilities, having the ability to annotate and highlight, getting rid of endnotes in favour of footnotes, as well as wanting better indexing. Moreover, readers want more dynamic, interactive and updatable content befitting of digital formats, access to supplemental information including datasets, more use of graphics and multimedia content, as well as embedded links within the text; for example to web-links, references, datasets and other associated multimedia content.

Respondents expressed their desire for the format of digital and e-book editions to be improved and better adapted for these new mediums. As part of this, there was a desire for better graphics. A few respondents also commented on their wanting for the format of digital and e-book editions to mimic print editions, including page numbering and illustrations.

\section{Using and engaging with monographs in all formats}

Figure 1: When accessing a monograph, how likely is it that you would ... 


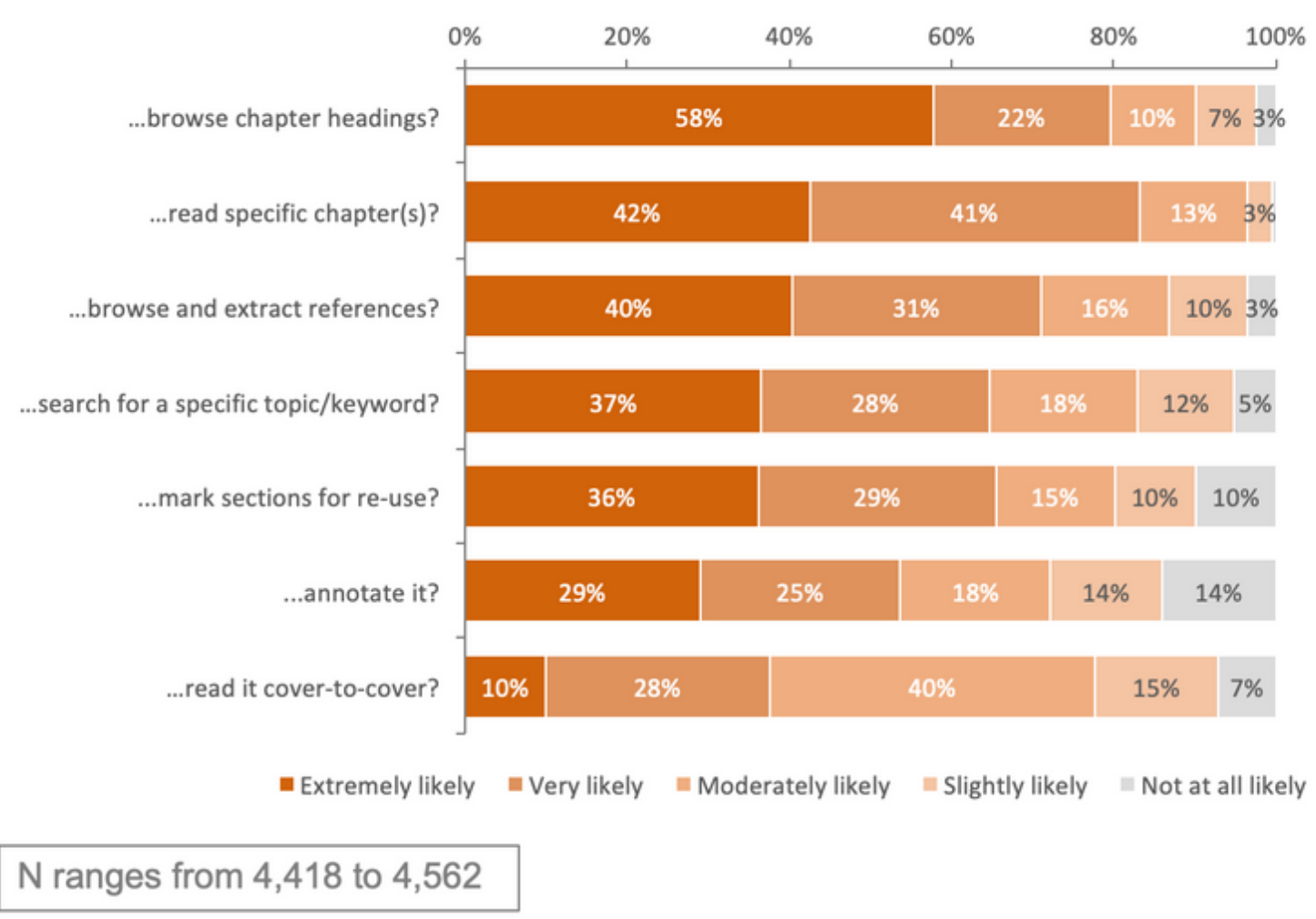

Readers often engage with monographs on a chapter level: When accessing a monograph, over $80 \%$ of respondents indicated they were 'extremely' or 'very' likely to browse chapter headings and read specific chapters. Over $70 \%$ were 'very' or 'extremely likely' to browse and extract references and over $50 \%$ were likely to annotate it. Less than $40 \%$ were 'very' or 'extremely likely' to read a monograph coverto-cover.

Figure 2: When accessing a monograph, how likely is it that you would ... 


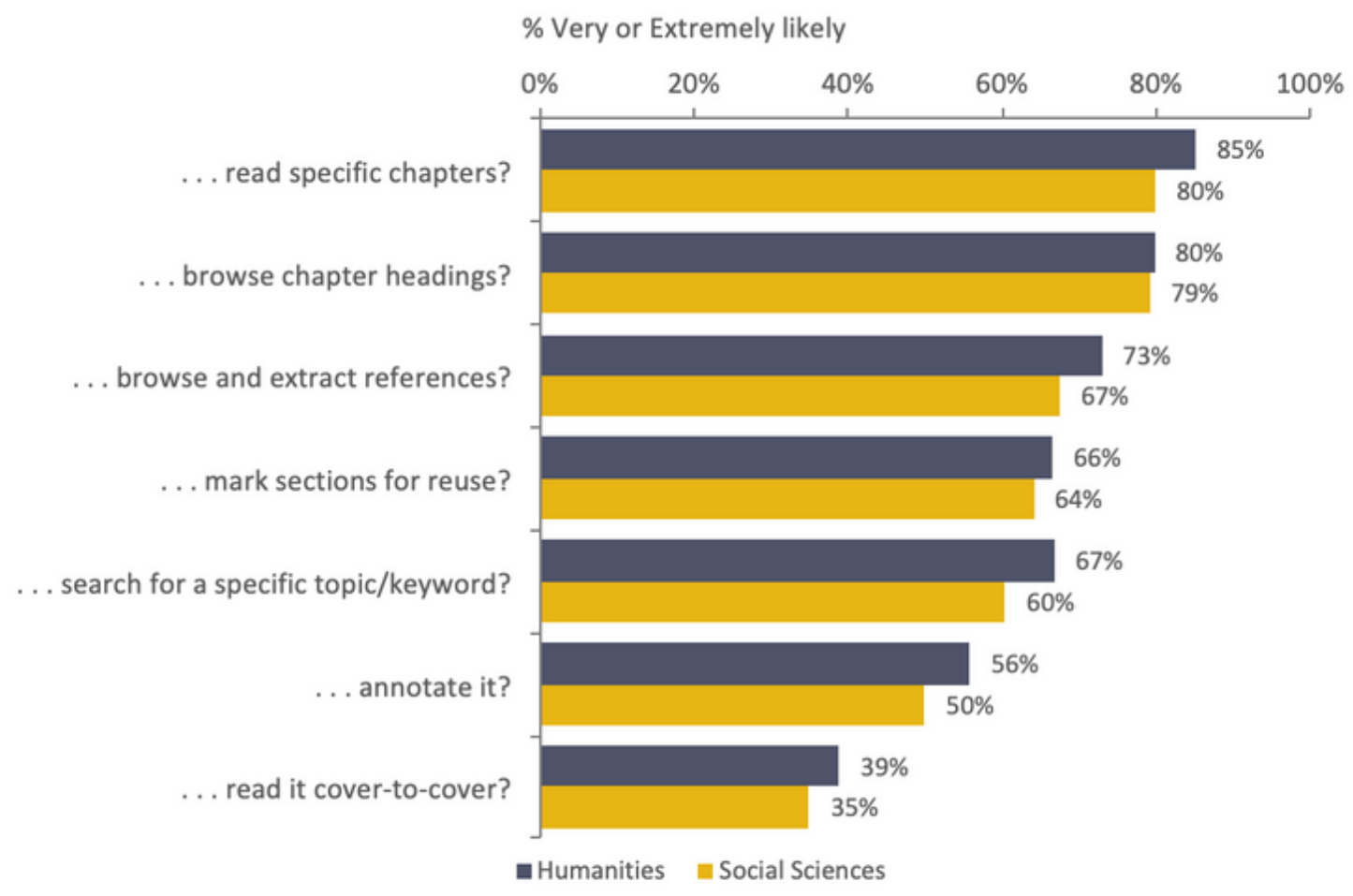

$\mathrm{N}$ ranges from 4,277 to 4,386

\section{Humanities researchers are more likely to engage with monographs in a} variety of ways: A total of $85 \%$ of the Humanities respondents were 'very' or 'extremely' likely to read a specific chapter in a monograph, compared with $80 \%$ in the Social Sciences. Further, 39\% of the Humanities respondents were 'very' or 'extremely' likely to read a monograph cover-to-cover compared with $35 \%$ of the Social Sciences respondents.

Figure 3: When accessing a monograph, how likely is it that you would ... 


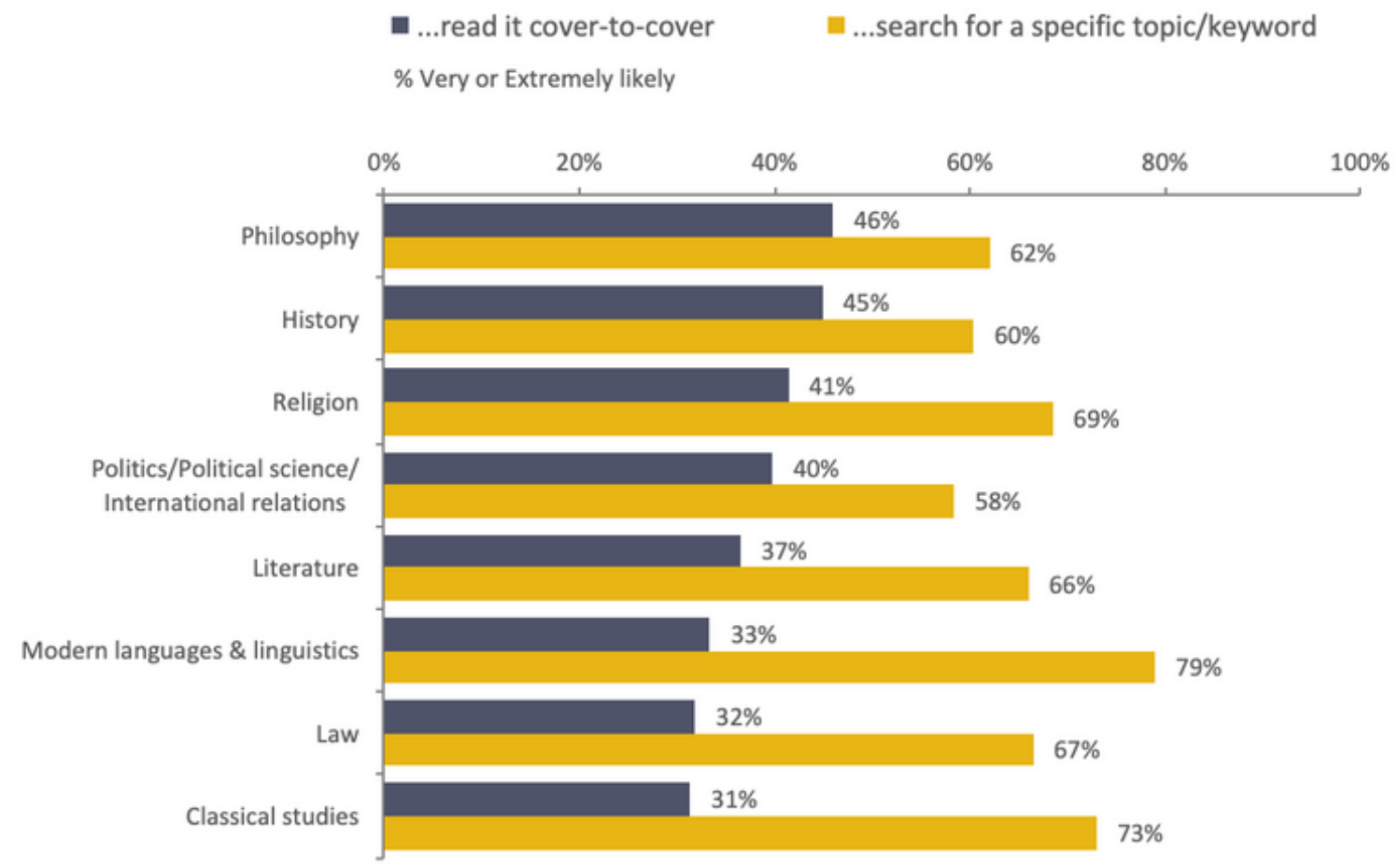

$\mathrm{N}$ ranges from 4,277 to 4,386

An analysis at subject level showed that researchers in Philosophy (46\%) and History (45\%) are slightly more likely to read monographs cover-to-cover compared with those in Classical Studies (31\%) and Law (32\%). Further, researchers in Modern Languages \& Linguistics (79\%) and Classical Studies (73\%) are more likely to search a monograph for a specific topic or keyword compared with those in Politics/Political Science/International Relations (58\%), and History (60\%).

Career stage affects how researchers engage with monographs: Browsing and searching behaviour were more prominent in early career researchers whereas reading cover-to-cover was more prominent in late career researchers.

Figure 4: When accessing a monograph, how likely is it that you would ... 


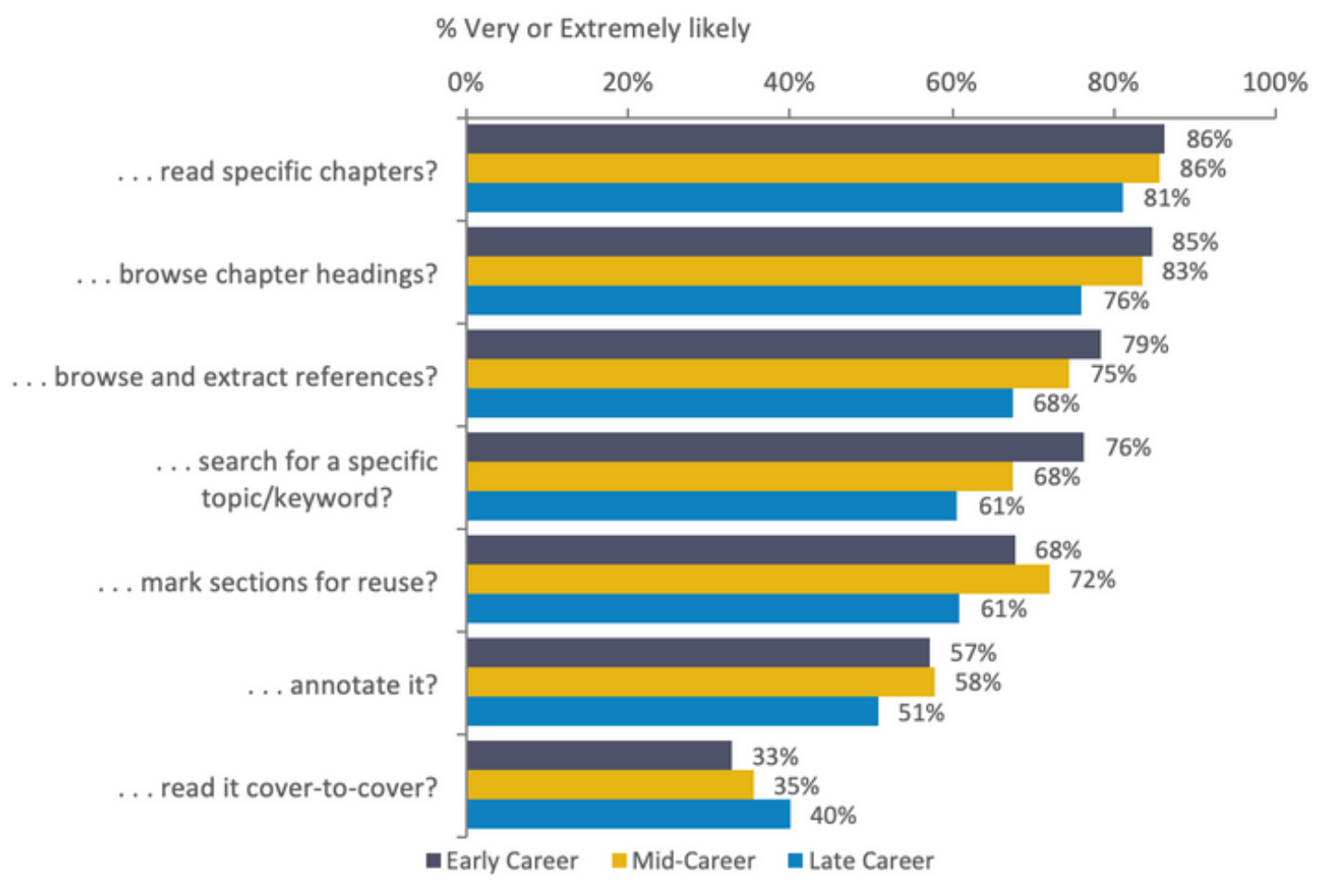

$\mathrm{N}$ ranges from 3,808 to 3,932

The largest proportion of a researcher's reading time is typically spent with journal articles and monographs: Respondents were asked to estimate what proportion of their scholarly reading time was spent with each format type. Figure 5 illustrates the proportional split based on our typical respondent (using median values).

Researchers in the Humanities typically spend slightly more time reading monographs than those in the Social Sciences: This finding is consistent with the slightly greater importance placed on journal articles in the Social Sciences.

Figure 5: Thinking of the time you spend reading scholarly literature, please indicate approximately what proportion of that reading time is spent with each of the following sources (illustration of the proportional split, based on median values): 


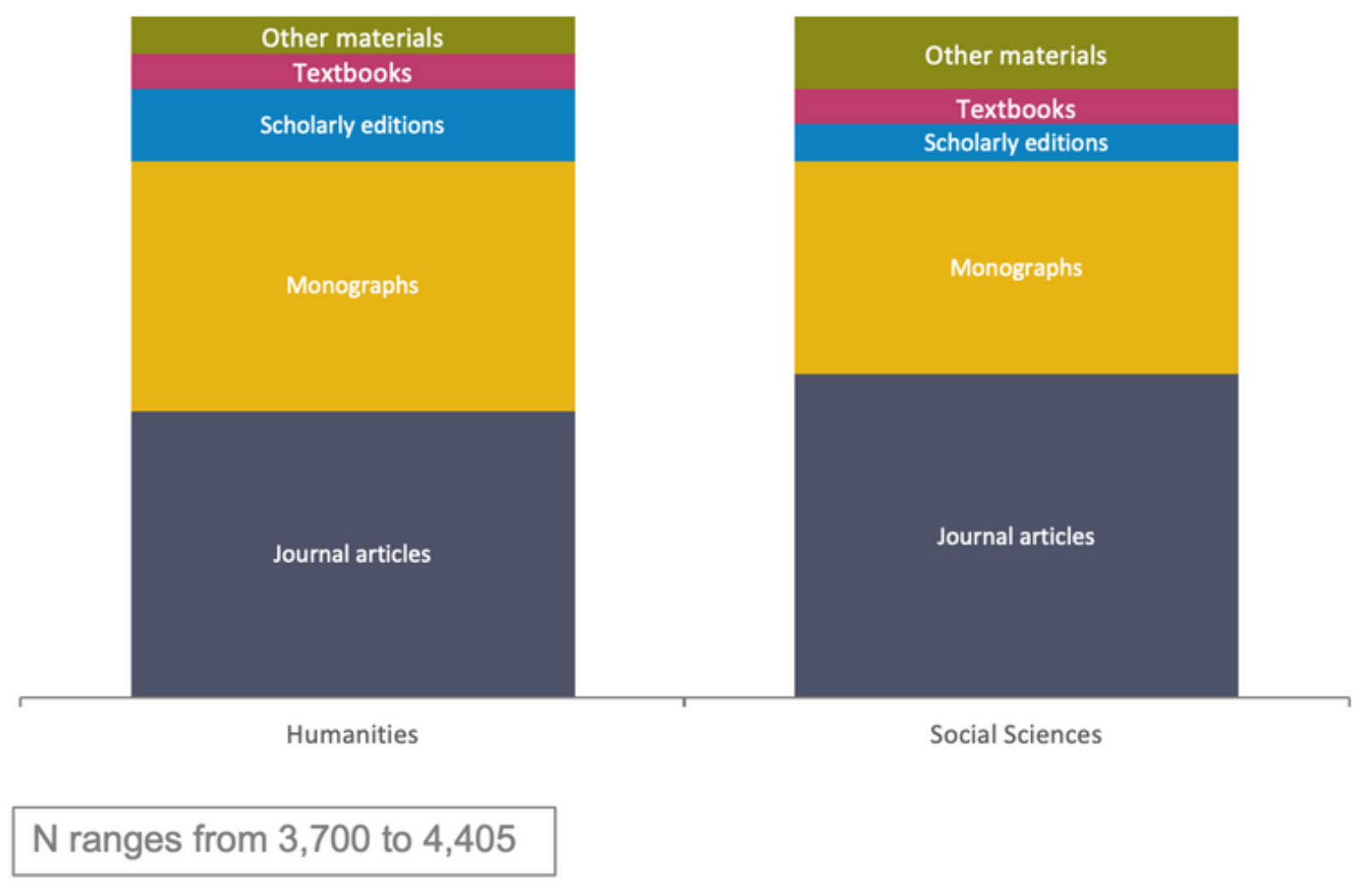

Monographs are important throughout research and teaching: Respondents indicated that they are 'extremely' or 'very' likely to read or refer to monographs in a range of situations in research and teaching. In particular, monographs play an important role in compiling lists of literature and synthesising literature. This suggests that researchers value the function of monographs in collating information in one place. Monographs are also a way to keep up-to-date with a particular author or subject.

Figure 6: How likely is it that you would read or refer to a monograph when doing the following? 


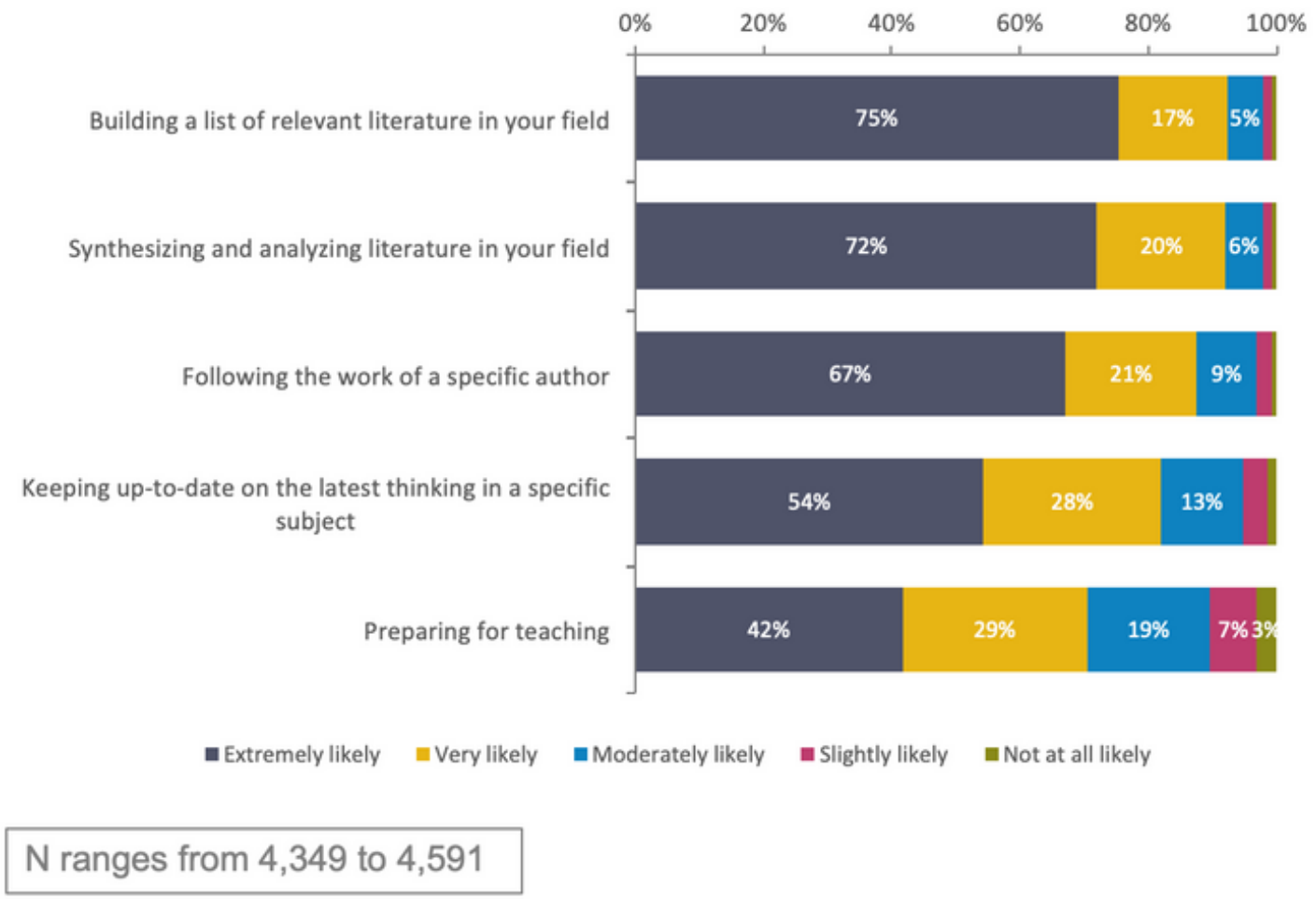

A regional analysis showed that researchers outside North America, the United Kingdom, and the rest of Europe are slightly less likely to refer to monographs when undertaking these tasks.

Figure 7: How likely is it that you would read or refer to a monograph when doing the following? 


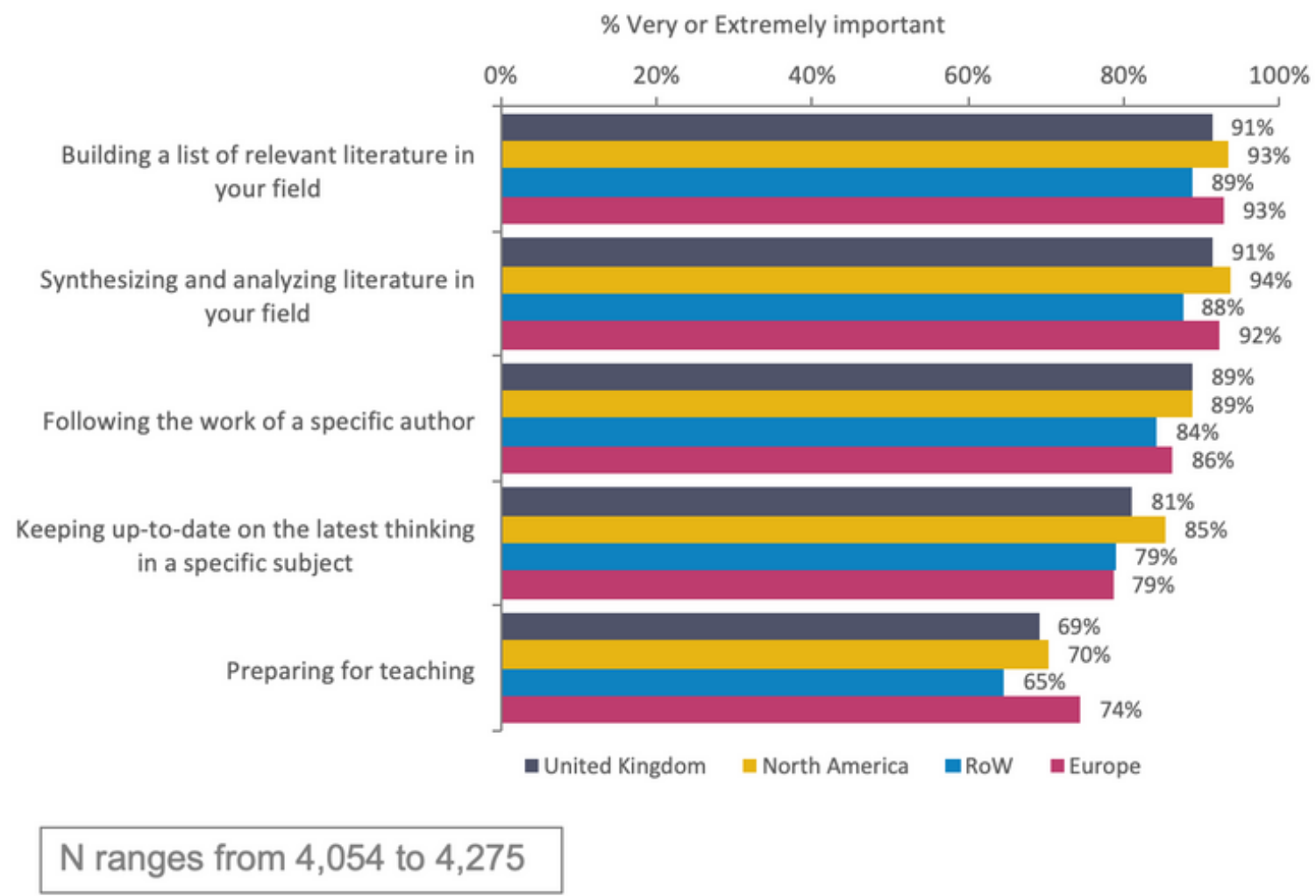

Additional reasons for reading or referring to monographs: Respondents had the opportunity to specify additional reasons for reading monographs or to expand on their responses more generally. Some specifically mentioned the importance of reading and referring to monographs whilst writing, as well as gaining knowledge on new and unfamiliar topics and fields. Others mentioned reading for pleasure and advising students.

“Obviously, I should think, preparing to write a monograph! Or article, or review. In short, I would be extremely likely to consult monographs in my scholarly writing." [Humanities, late-career researcher]

"As an entry to other relevant fields other than my own in questions that guide my work, when the author has engaged with multiple disciplines." [Social Sciences, early-career researcher]

"I also just think some monographs in literary criticism and philosophy are well written and interesting on their own." [Humanities, late-career researcher] 


\section{What do researchers want as monographs evolve digitally?}

\section{What should change?}

Respondents were asked to think broadly about reading, writing, and publishing monographs and what they would change if they could change one thing. All responses were systematically coded. Responses were very varied but the main themes are drawn out under the categories of reading, writing, and publishing monographs, with a final theme on the perceived importance of the monograph.

To better understand some of the developments readers want to see as monographs evolve digitally, further analysis was undertaken on a sub-set of feedback for this question, where responses related to monographs in a digital environment; these are highlighted in our Digital in-focus.

Reading monographs: Under the broad theme of reading, the most dominant response related to access, with many comments on the price of the monograph, which is often considered to be too expensive for an individual buyer, and sometimes not affordable for libraries. Therefore, respondents suggested printing more monographs in paperback or moving to digital-only publishing, possibly with open access. However, some respondents specified they prefer reading print but would like to have a digital version alongside for quick reading and searching. Others suggested e-reader-friendly editions.

“Their price! I keep buying monographs and quite frankly it's an unmanageable budget. Everything else I would keep as is :)" [Humanities, early-career researcher]

"Greater online availability of monographs, in the same way that journal articles can be accessed. I strongly believe the (lack of) ease of access is the primary obstacle to greater dissemination of monograph material today." [Social Sciences, mid-career researcher]

\section{Digital in-focus}

Responses show that digital access and search capabilities are important to readers. To improve the usability of digital monographs readers also want the ability to 
annotate. As part of this, respondents wanted to be able to organise, store and export annotations, as well as having the ability to highlight.

"Having them online/digital and therefore searchable would be great." [Humanities, mid-career researcher]

"Making them accessible using online platforms, easily findable and usable. More automized and integrated technologies in them." [Humanities, early-career researcher]

"To have the ability to annotate, search, retrieve, and store sections/passages of a monograph digitally." [Humanities, late career researcher]

Writing monographs: Under the broad theme of writing monographs, the most common response related to time. Many commented about a lack of time to write (and read)-especially due to their teaching load which they felt does not allow sufficient time for research. Others commented on the desire for shorter content and the need for a midlength category (e.g., 30,000-60,000 words), between journal articles and monographs. Another suggested change was for authors to use more accessible language so that the monograph could appeal to a broader group.

"Academics need more research time. To achieve this, universities need to significantly reduce the administrative and meeting burden on academics." [Humanities, mid-career researcher]

"Perhaps more options for publishing a shorter monograph of 60,000 words or so. There is no format between a 10k journal article and an 80-100k book." [Humanities, mid-career researcher]

Publishing monographs: Under the broad theme of publishing monographs, some focused on the editorial review processes, with comments about the time between manuscript submission and publication often being too long, especially for those from fast-moving fields where timeliness was particularly valued. Additionally, some made suggestions around improving the editing process, production, copy-editing, and proofreading. Others criticised the double-blind peer review system and felt limited by not being able to react to reviewers' comments. Respondents suggested adding 
supplementary material (e.g., videos, images, maps, interactive elements) to the book online. Some requested endnotes to be abolished and footnotes to be used instead and others asked for the quality of graphics to be improved.

Others considered that too many monographs are being published, and of these, too many of poor quality. Many felt that there is a lot of pressure on young academics to publish soon after graduation to get tenure or for the UK REF, resulting in researchers publishing PhDs that may be little read. However, some suggested that presses should be more open to publishing original ideas and should support creativity and give authors more freedom.

"Make the publishing process faster so that the information is not so out of date by the time the monograph is published." [Social Sciences, late- career researcher]

"Publishers are not keeping up with research trends, for example, the visual turn in history writing. Publishers continue to dislike publishing images but the field is increasingly using them. So we have a disconnect." [Humanities, late-career researcher]

"Less quantity, more quality (way too many monographs being published without necessarily being convincing or even really good); giving chances to YOUNG scholars and not to accomplished scholars." [Humanities, early-career researcher]

\section{Digital in-focus}

Respondents indicated that they wanted more dynamic, interactive and updatable content befitting of digital formats, access to supplemental information including datasets, more use of graphics and multimedia content, as well as embedded links within the text; for example to web-links, references, datasets and other associated multimedia content. As part of this, there was a desire for better graphics. A few respondents also commented on their wanting for the format of digital and e-book editions to mimic print editions, including page numbering and illustrations.

"Find formats that can enrich monographs with multimedia content - online, born digital perhaps - the way journal articles increasingly do" [Social Sciences, midcareer researcher] 
"I would like monographs to evolve to include dynamic, easily accessible webbased features, with the objectives of bringing the work to different audiences and enabling more real-time engagement." [Humanities, late-career researcher]

"The ability to integrate digital data into the monographic narrative more richly. Supplemental data files are fine, but I want to present narrative and data together." [Humanities, late-career researcher]

General importance: Finally, as a general comment, some readers once again took the opportunity to stress the value of the monograph. Comments were made about consideration for the importance of monographs in general, with the desire for the monograph to be more appreciated in their particular field. There were also many who suggested that nothing should change.

"I would give back more importance to monographs rather than journals." [Humanities, early-career researcher]

"I would change nothing. Despite the publishing difficulties for monographs, they have vital importance in the humanities. I seek them out for review, I read them cover to cover, I keep them for citation in published research." [Humanities, latecareer researcher]

\section{Digital in-focus}

Overall, respondents vocalised their desire for the format of digital and e-book editions to be improved and better adapted for these new mediums. While many respondents encouraged the shift to digital monographs, they particularly wanted the readability and interface of digital and ebook editions to be improved.

“The electronic interfaces for reading monographs cover to cover are awful. They are in need of serious improvement if the current trend toward electronic books continues." [Social Sciences, mid-career researcher]

"E-book formats must be taken seriously and improved. That is not the same thing as a website or blog." [Humanities, early-career researcher] 
"Better online infrastructure. While I think the monograph remains important, I wish there were more innovative ways to develop and redeploy the medium online. Move beyond the simple pdf and towards a more complex online model." [Humanities, mid-career researcher] 